IZA DP No. 7303

The Assignment of Workers to Tasks with Endogenous Supply of Skills

Arnaud Dupuy

March 2013 


\title{
The Assignment of Workers to Tasks with Endogenous Supply of Skills
}

\author{
Arnaud Dupuy \\ CEPS/INSTEAD, \\ Maastricht School of Management and IZA
}

Discussion Paper No. 7303

March 2013

\author{
IZA \\ P.O. Box 7240 \\ 53072 Bonn \\ Germany \\ Phone: +49-228-3894-0 \\ Fax: +49-228-3894-180 \\ E-mail: iza@iza.org
}

Any opinions expressed here are those of the author(s) and not those of IZA. Research published in this series may include views on policy, but the institute itself takes no institutional policy positions. The IZA research network is committed to the IZA Guiding Principles of Research Integrity.

The Institute for the Study of Labor (IZA) in Bonn is a local and virtual international research center and a place of communication between science, politics and business. IZA is an independent nonprofit organization supported by Deutsche Post Foundation. The center is associated with the University of Bonn and offers a stimulating research environment through its international network, workshops and conferences, data service, project support, research visits and doctoral program. IZA engages in (i) original and internationally competitive research in all fields of labor economics, (ii) development of policy concepts, and (iii) dissemination of research results and concepts to the interested public.

IZA Discussion Papers often represent preliminary work and are circulated to encourage discussion. Citation of such a paper should account for its provisional character. A revised version may be available directly from the author. 


\section{ABSTRACT}

\section{The Assignment of Workers to Tasks with Endogenous Supply of Skills*}

This paper presents a general equilibrium assignment model of workers to tasks with endogenous supply of skills. The model has 2 key features. First, skills are endogenous and multidimensional. Second, two types of assignment occur; workers self-select the type of skills to supply and firms assign workers to tasks/machines. Equilibrium is characterized by two functions mapping skills of each type to tasks and two wage functions, one for each type of skills, so that the wage distributions generally overlap. The model shows that the impact of any given skill-biased technical change on wage inequality is tightly related to the distribution of skills in the population. Productivity effects can be over or under estimated by wage data when the supply of skills is endogenous. The model also shows that Johnson's (1997) distinction between intensive and extensive technical change is impossible when supply is endogenous.

JEL Classification: D3, J21, J23, J31

Keywords: tasks assignment, endogenous supply of skills, multidimensional skills, human capital, technical change, wage distribution

Corresponding author:

Arnaud Dupuy

CEPS/INSTEAD

3, avenue de la Fonte

L-4364 Esch-sur-Alzette

Luxembourg

E-mail: arnauddupuy74@gmail.com

\footnotetext{
* The comments of participants at various conferences and seminars and especially Daron Acemoglu, Lex Borghans, Jeremy Fox, Bart Golsteyn, Hans de Graaff, Andries de Grip, James Heckman, Hans Heijke, Frank Levy, Derek Neal, Jean-Marc Robin, Gerard Pfann, Michael Sattinger, Robert Shimer, Coen Teulings, Bas ter Weel and Editor Peter Sorensen and two anonymous referees are acknowledged.
} 


\section{Introduction}

This paper is about the assignment of heterogenous workers to heterogenous tasks and the impact of technical change on the distribution of wages. In the existing literature on assignment models of wage distribution (see Sattinger, 1975, 1979 and 1993, Teulings, 1995a, 1995b and 2005, Costrell and Loury, 2004), wage differentials between workers arise from productivity differentials between workers. These productivity differentials are initiated by exogenous skills differentials and magnified through the assignment of more able workers to more productive tasks in equilibrium. The equilibrium wage structure therefore depends crucially on the distribution of skills, the distribution of tasks and the productivity of worker-task pairs. This means that changes in the wage structure could arise through the human factor 11 i.e. changes in the distribution of skills, or through the technical factor, i.e. changes in the distribution of tasks. ${ }^{2}$ but also through changes in the productivity of worker-task pairs over time. ${ }^{3}$ For instance, Gabaix and Landier (2008) and Terviö (2008) exploit this unique feature of assignment models to explain (the rise in) CEO pay differentials. Both studies conclude that the distribution of managerial talent is in fact not very dispersed and that the bulk of (the rise in) CEO pay differentials is due to firms characteristics, i.e. the technical factor.

A standard assumption in these models, however, is that the distribution of skills is exogenous. This implies that technical change is allowed to affect the wage distribution through changes in the equilibrium wage function but not through changes in the distribution of skills. This seems to be a stark assumption for two main reasons. First, as soon as workers' skills are multidimensional, - as argued by Bertrand and Schoar (2003) and Bloom and Van Reenen (2007) in the case of managerial talent for instance- technical change that affects the relative demand for certain types of skills will most likely affect workers' supply of skills in equilibrium. Second, in the light of the human capital theory, investments in human capital (higher or different types of skills) depend crucially on (expected) wages. One might therefore expect that technical changes will generally affect human capital investment decisions and hence the distribution of skills.

This paper contributes to the assignment models literature by endogenizing the distribution of skills in a general equilibrium assignment model of

\footnotetext{
${ }^{1}$ I owe the terminology technical factor versus human factor to Frank Levy.

${ }^{2}$ Think for instance of the job polarization observed in the US (see Autor et al., 2006) and UK (see Goos and Manning, 2007) in recent years.

${ }^{3}$ See Dupuy (2009) for an overview of the literature on the impact of technical change in assignment models.
} 
workers to tasks. In the model, workers are endowed with a vector of skills and supply their skills of the type maximizing their earnings. As a result, the equilibrium supply of skills of each type in the economy is a truncation of the marginal distribution of each type of skills as in Roy's (1950 and 1951) model.

Two types of assignment occur in the model. The first type of assignment is workers' self-selection of the type of skills to supply. With some additional assumptions about foresight and the structure of the educational system, it is possible to link this self-selection of the type of skills to supply to educational self-selection as in Willis and Rosen (1979). In this extension of the model, workers are endowed with initial skills (abilities) that are magnified through education. Educational choice determines which type and level of skills workers will supply to the market. This extension of the model allows us to take into account explicitly the impact of technical change on human capital investments in a general equilibrium assignment model.

The second type of assignment is the assignment of workers to tasks. Each task refers to a different type of machine. To produce output, this machine needs to be operated by one and only one worker. Although the various machines can be operated by workers with different types and levels of skills, workers of different types and levels of skills differ in their productivity. For instance, if productivity is so that i) workers of each skills type have a comparative advantage on a different side of the support of tasks, ii) within types of skills, more skilled workers have an absolute advantage and iii) workers' skills complement the characteristics of machines in production then, following Ricardo's principles of comparative advantage $\AA^{4}$ and differential rents, equilibrium in this model is characterized by two mapping functions, one for each type of skills supplied. The first mapping function is decreasing and maps skills of the first type to tasks on the left hand side of the support. The second mapping function is increasing and maps skills of the other type to tasks on the right hand side of the support. These two mapping functions generate two wage functions, one for each type of skills, that will in general overlap.

The model presented in this paper offers a new framework to analyze the impact of technical change on i) the structure of wages, both within and between skills groups of workers, and ii) the supply of skills. It relates to the enlightening work by Acemoglu and Autor (2011) who developed a taskbased model to explain patterns of rising wage inequality observed over the

\footnotetext{
${ }^{4}$ The theory of comparative advantage in labor markets was formally developed by Sattinger (1975) (see also Sattinger (1993) for a survey of assignment models and comparative advantage) and the presence of comparative advantage was later demonstrated empirically in Sattinger (1978 and 1980).
} 
last 6 decades in most developed countries. The task-based approach has the advantage upon existing assignment models to be relatively more tractable while allowing the crucial distinction between skills and jobs. However, this advantage vanishes as soon as one allows the supply of skills to be endogenous as is apparent in the brief discussion of this extension in Acemoglu and Autor (2011).

In this paper, I show that even though the assignment model with endogenous supply of skills is not generally tractable, it delivers new qualitative predictions of how skill-biased technical change (SBTC) can impact the distribution of wages. A qualitative exercise indeed shows how the model can be used to interpret in a new light stylized facts about the distribution of wages in the US over the last 6 decades as illustrated in Figure 1 and consistent with Acemoglu (2002) and Acemoglu and Autor (2011). For instance, a striking development in the US wage structure is the fact that wage inequality rose within education while the college premium remained at the same level between 1965 and 1980. The model presented in this paper predicts that, following a SBTC, for the between wage inequality to remain constant at the same time that within wage inequality rises, requires the supply of college graduates to increase (see Proposition 3). This increase in supply is observed in the data and has already been offered as an explanation for the differential timing of the within and between education rise in wage inequality (see e.g. Katz and Murphy, 1992). However, the current interpretation is that this supply shift is coincidental and corresponds to the additional college enrolment caused by the baby boom cohort and the Vietnam war. This paper investigates the extent to which this change in the supply of skills could be the endogenous response of workers to technical change. Topel (1997) showed evidence of a long run response of supply: college enrolment seemed to follow closely the evolution of the college premium. In the multidimensional skills model presented in this paper, the response of supply could also happen in the short run as workers, that are endowed with multiple skills, may decide to supply different types of skills over time following their comparative advantage.

The paper shows that, when workers can choose the type of skills they supply in the short run, the impact of any given SBTC on wage inequality is tightly related to the distribution of skills in the population and in particular the correlation between the types of skills and the respective concentration of skills (variance). If skills are positively correlated in the population and manual skills are relatively less concentrated, then the observed between wage inequality overestimates the true productivity effect of SBTC (the effect at constant supply of skills). In contrast, if skills are negatively correlated and manual skills are relatively less concentrated, then the observed between wage 
inequality underestimates the true productivity effect of SBTC.

A second interesting insight of the model concerns the "nature" of SBTC. Johnson (1997) distinguishes between two types: intensive SBTC that increases the productivity of college workers in the tasks they used to perform, and extensive SBTC that increases the productivity of college workers in tasks that are usually performed by high-school workers. Interestingly enough, in the later situation, the range of tasks performed by college workers widens while the range of tasks performed by high-school workers narrows. The model presented in this paper shows that even in the face of an intensive SBTC, because of the endogenous supply response of workers, the supply of college graduates increases such that firms will reassign tasks that were previously performed by high-school graduates to college graduates. An intensive SBTC turns into an extensive SBTC through the skills supply response of workers. It becomes impossible to distinguish between the two types of SBTC when supply is endogenous.

To my knowledge, the assignment model in this paper is the only model that yields two mapping functions and hence two wage functions in equilibrium. However, among others, Lucas (1978), Rosen (1982) and more recently Garicano and Rossi-Hansberg (2006) and Candelon and Dupuy (2012) developed one-sided assignment models in which two types of assignment occur. First, depending on their abilities, agents are assigned to occupations, either worker or manager. Above a certain threshold of ability agents become managers while below that threshold, agents become workers. After this initial assignment, groups of workers are assigned to managers. However, these models give rise to a single mapping function that maps ability to occupations. Hence, equilibrium is characterized by a single monotonic wage function so that the most able worker earns less than the least able manager, there is no overlap between the earnings of workers and managers. Interestingly enough, Epple et al. (2006) developed a general equilibrium model of the market for higher education in which students are heterogenous in terms of (household) income and endowed ability and colleges are heterogenous in terms of (mean students) quality and tuition. The problem for students is to choose the college that maximizes their (household) utility and the problem for colleges is to maximize (peer-)quality by setting the appropriate selection rule and tuition level. In equilibrium, each college has a distinct admission rule. These decision rules slant the income/ability plan into regions (colleges) in a way that is analogous to the assignment of agents to occupations in one-sided assignment models.

This paper is also related to a thin literature in "macroeconomics" studying the interaction between endogenous human capital formation and technical change (e.g. Eicher, 1996, Crifo, 2008). This literature focuses on 
the impact of SBTC on growth and the college premium allowing for an endogenous response of supply, i.e. educational choice. The present paper contributes to this literature by studying the impact of SBTC on workers' supply of skills, tasks assignment and the resulting changes in the structure of wages both between and within skills groups.

The remaining structure of the paper is as follows. Section 2 discusses the model of tasks assignment with endogenous supply of skills. Section 3 studies the impact of an intensive SBTC on the structure of wages and the tasks assignment. Section 4 concludes.

\section{A tasks assignment model with endogenous supply of skills}

\section{$2.1 \quad$ Set up}

Supply of skills

Let workers be endowed with a vector of skills $t=\left\langle t_{1}, t_{2}\right\rangle \in R_{+}^{2}$ where $t_{1}$ and $t_{2}$ represent an individual's skills of type 1 and 2 , manual and intellectual skills for the sake of the argument. Let $\xi\left(t_{1}, t_{2}\right)$ and $\Theta\left(t_{1}, t_{2}\right)$ be respectively the probability density function and cumulative density function of workers' skills. Let $\Theta$ be absolutely continuous with respect to Lebesgue measure. 5

Assume that workers can only use one type of skills at a time so that workers with skills $\left\langle t_{1}, t_{2}\right\rangle$ can supply $t_{1}$ units of skills of type 1 for a share $\tau$ of their working time and supply $t_{2}$ units of skills of type 2 the rest of their working time. Their earnings are given by $\tau w_{1}\left(t_{1}\right)+(1-\tau) w_{2}\left(t_{2}\right) !^{6}$ We assume that the economy is competitive such that workers take $w_{k}\left(t_{k}\right)$ as given. As a result, earnings maximization is equivalent to:

$$
\max _{j=1,2} w_{j}\left(t_{j}\right)
$$

\footnotetext{
${ }^{5}$ Note that we do not impose any restrictions on the distribution of skills in the population: in particular, the correlation between skills of the two types in the population is free to vary on its full support $[-1,1]$. As in all self-selection models, the sign and the magnitude of the correlation will play a central role in the equilibrium distributions of skills and hence in the impact of technical change on wage inequality (see Section 3).

${ }^{6}$ Note that any convex function of $\tau w_{1}\left(t_{1}\right)$ and $(1-\tau) w_{2}\left(t_{2}\right)$ yield the corner solution $\tau=0$ or $\tau=1$. In Lazear's (2005) terminology, this means that my workers are assumed to be specialists, Lazear's entrepreneurs are excluded from the model. Note that in empirical work on wage inequality, the self-employed are usually excluded from the sample.
} 
As shown below in Result $2, w_{j}($.$) are monotonic strictly increasing func-$ tions and hence invertible. Let $t_{j}^{*}\left(t_{k}\right) \equiv w_{j}^{-1}\left(w_{k}\left(t_{k}\right)\right)$ with $t_{j}^{* \prime}\left(t_{k}\right)>0$ since $w_{j}^{\prime}()>$.0 . Workers whose skills $t_{j}$ exceeds $t_{j}^{*}$ follow their comparative advantage and supply type $j$ skills. Note that $t_{j}^{*}$ is a strictly increasing function of $t_{k}$ that could be concave, linear, convex or even locally concave and locally convex depending on the structural parameters. This contrasts to Willis and Rosen's (1979) application of Roy's model in which $t_{j}^{*}$ is a linear function of $t_{k} \cdot{ }^{7}$

The density of workers supplying $t_{k}$, say $\xi_{k}\left(t_{k}\right)$, is a truncation of the marginal density of $\xi\left(t_{1}, t_{2}\right)$ along the selection curve $t_{j}<t_{j}^{*}\left(t_{k}\right)$ for $j \neq k$, and is defined parametrically as:

$$
\begin{aligned}
& \xi_{1}\left(t_{1}\right)=\int_{0}^{t_{2}^{*}\left(t_{1}\right)} \xi\left(t_{1}, t_{2}\right) \cdot d t_{2} \\
& \xi_{2}\left(t_{2}\right)=\int_{0}^{t_{1}^{*}\left(t_{2}\right)} \xi\left(t_{1}, t_{2}\right) \cdot d t_{1} .
\end{aligned}
$$

Note that the density of workers supplying skills $t_{k}$ depends on the wage functions $w_{j}\left(t_{j}\right), j=1,2$, through $t_{j}^{*}\left(t_{k}\right)$.

\section{Demand for skills}

The economy considered produces a composite commodity by means of the input of different tasks. Each task is associated with a unit of capital, a machine for the sake of the argument, and the various tasks correspond to machines with different characteristics 8 To produce output, each machine needs to be operated by a fixed proportion of workers, i.e. one and only one worker. The owner of a machine is loosely referred to as a firm. In this economy, output $Y$ is obtained by summing up the production in each single task.

\footnotetext{
${ }^{7}$ In a single cross-section, the nonlinearity of relative wages does not matter since one could simply change the scales of both skills so as to obtain a linear functional form. However, when one is concerned by the impact of technical change on the wage structure, one compares several economies, and one must hold the scale of skills constant across economies.

${ }^{8}$ This part of the model is to a large extent similar to the differential rents models described in Sattinger (1979 and 1993). The terminology "task" and "machine" are interchangeable throughout the paper. In general I will use "task" for the sake of simplicity but when needed I will refer explicitly to machines.
} 
Output at each task can be produced by workers supplying different types and levels of skills but workers of different types and levels of skills differ in their productivity. For instance, while a worker supplying intellectual skills could operate a circular saw with some productivity, a worker supplying manual skills would probably be more productive. Similarly, while a worker supplying manual skills could use a computer productively, a worker supplying intellectual skills would probably make better use of the same computer. These examples suggest that, under certain assumptions, machines could be ranked on a one dimensional support. The position of machines on this support would indicate a gradual change from extremely manual machines to extremely intellectual machines as we move from the left to the right.

The required assumptions for the support of tasks to be unidimensional are better understood with the following experiment in mind. Suppose we assign a randomly chosen worker supplying manual skills successively to each task of this economy and rank these tasks by decreasing productivity. Similarly, we assign a randomly chosen worker supplying intellectual skills successively to each task and rank the tasks by increasing productivity. The first fundamental assumption about the support of tasks is that the ranking of tasks would be exactly the same in both cases, meaning that the most manual tasks are also the least intellectual ones and vice versa. Note that this assumption is a sufficient condition for comparative advantage of types of skills to arise. Workers supplying manual skills have a comparative advantage in low ranked, manual, tasks and workers supplying intellectual skills have a comparative advantage in high ranked, intellectual, tasks.

The second fundamental assumption about the support of tasks is that the ranking of tasks is the same for all workers, or stated otherwise, does not depend on the level of skills supplied. A sufficient condition for the rank of tasks to be the same for all workers is the complementarity between machines and skills. The complementarity assumption stipulates that the change in productivity associated with an increase in the level of manual (intellectual) skills is larger in more manual (respectively intellectual) tasks. Hence, increasing the level of manual (intellectual) skills would level up the output in tasks with low (respectively high) rank compared to tasks with high (low) rank but would not affect the rank of tasks.

Given these two assumptions we can define the support of tasks as follows. Let $v$ denote a task and, without loss of generality, let the support of task be the unit interval $(0,1)$, with tasks $v$ increasing from 0 to 1 as the rank of tasks defined above increases. To fix ideas, tasks close to 0 are for instance the tasks of a carpenter and tasks close to 1 are the tasks of a rocket scientist. Similarly, machines close to 0 could be circular saws and machines close to 1 could be computers. Tasks in the middle of the support are the "anybody 
can do it as efficiently" tasks.

Once the support of tasks is defined, the productivity of a worker with $t_{k}$ units of skills of type $k$ when assigned at task $v$ can be defined by the function $p_{k}\left(v, t_{k}\right)$. By definition of the support of tasks, the comparative advantage assumptions implies $\frac{\partial p_{1}\left(v, t_{1}\right)}{\partial v}<0$ and $\frac{\partial p_{2}\left(v, t_{2}\right)}{\partial v}>0 \forall v, t_{k}$ and the complementarity assumption implies $\frac{\partial^{2} p_{1}\left(v, t_{1}\right)}{\partial t_{1} \partial v} \leq 0$ and $\frac{\partial^{2} p_{2}\left(v, t_{2}\right)}{\partial t_{2} \partial v} \geq 0 \forall v, t_{k}$. To these two assumptions, it seems reasonable to add an absolute advantage assumption indicating that more skilled workers are more productive at all tasks. As it will be shown below, this assumption guarantees that equilibrium wages increase with the level of skills. The absolute advantage assumption implies $\frac{\partial p_{k}\left(v, t_{k}\right)}{\partial t_{k}}>0 \forall v, t_{k}$. These assumptions are summarized in Assumption A.

\section{Assumption A:}

i) Comparative advantage of skills types, i.e. $\frac{\partial p_{1}\left(v, t_{1}\right)}{\partial v}<0$ and, $\frac{\partial p_{2}\left(v, t_{2}\right)}{\partial v}>0$ $\forall v, t_{k}$,

ii) absolute advantage of skilled workers, $\frac{\partial p_{k}\left(v, t_{k}\right)}{\partial t_{k}}>0 \forall v, t_{k}$,

iii) complementarity of skills types and machines, $\frac{\partial^{2} p_{1}\left(v, t_{1}\right)}{\partial t_{1} \partial v} \leq 0$ and, $\frac{\partial^{2} p_{2}\left(v, t_{2}\right)}{\partial t_{2} \partial v} \geq$ $0 \forall v, t_{k}$.

The distribution of tasks is assumed exogenous and let $f(v)$ and $F(v)$ be respectively the probability density function and the cumulative density function of $v$ and let $F$ be absolutely continuous with respect to Lebesgue measure.

Obviously, given assumption $A i$ ), an efficient assignment of workers to tasks will maximize output by assigning workers supplying skills of type 1 to tasks $(0, \varepsilon)$ and workers supplying skills of type 2 to tasks $(\varepsilon, 1)$ where the marginal task will be defined such that $F(v)=\int_{0}^{\infty} \xi_{1}(x) d x$ in equilibrium. ${ }^{9}$ Given assumption $A$ ii) and iii), among workers supplying skills of type 1, those with the highest level of skill 1 will be assigned to task 0 and so on until the marginal task $\varepsilon$ is assigned to those workers supplying the lowest level of skill 1 , say $t_{1, \varepsilon}$. By symmetry, the tasks $(\varepsilon, 1)$ are assigned to workers supplying skills of type 2. Workers supplying the lowest level of skills of type 2 , say $t_{2, \varepsilon}$, are assigned to task $\varepsilon$ and so on until those workers with the highest level of skills 2 are assigned to task 1 . The optimal assignment is such that a mapping function $v_{1}$ associates a single value of skills $t_{1}$ to

\footnotetext{
${ }^{9}$ Firms owing machine $\varepsilon$ are indifferent between employing a worker with type 1 or type 2 .
} 
each task $v \in(0, \varepsilon)$, i.e. $v=v_{1}\left(t_{1}\right)$ with $v_{1}^{\prime}\left(t_{1}\right)<0, \varepsilon=v_{1}\left(t_{\varepsilon, 1}\right)$ and $\lim _{t_{1} \rightarrow \infty} v_{1}\left(t_{1}\right)=0$, and a mapping function $v_{2}$ associates a single value of skills $t_{2}$ to each task $v \in(\varepsilon, 1)$, i.e. $v=v_{2}\left(t_{2}\right)$ with $v_{2}^{\prime}\left(t_{2}\right)>0, \varepsilon=v_{2}\left(t_{\varepsilon, 2}\right)$ and $\lim _{t_{2} \rightarrow \infty} v_{2}\left(t_{2}\right)=1.10$

As is well-known in the literature, this optimal assignment corresponds to the decentralized competitive assignment obtained from the firms' and workers' optimization problem. ${ }^{11}$ To see this, consider the firms' problem. A firm owning machine $v$ seeks to maximize the profits derived from its machine. The profits from assigning a worker with skills $t_{k}$ are $r(v) \equiv p_{k}\left(v, t_{k}\right)-w_{k}\left(t_{k}\right)$ and since the economy is competitive, firms take $w_{k}\left(t_{k}\right)$ as given. This firm will therefore compare the productivity increase to the wage increase associated with a worker with higher skills $t_{k}$. This yields the following First Order Conditions:

$$
\frac{\partial p_{k}\left(v, t_{k}\right)}{\partial t_{k}}=w_{k}^{\prime}\left(t_{k}\right) \forall k=1,2
$$

and Second Order Conditions

$$
\frac{\partial^{2} p_{k}\left(v, t_{k}\right)}{\partial t_{k}^{2}}-w_{k}^{\prime \prime}\left(t_{k}\right)<0 \forall k=1,2 .
$$

Note that from assumptions $A$ ii), we therefore have:

Result R1: $w_{k}^{\prime}\left(t_{k}\right)>0 \forall k=1,2$.

By the implicit function theorem, Equations 4 yield each an implicit function $v=v_{k}\left(t_{k}\right)$ for $k=1,2$ mapping workers skills of each type to tasks. Plugging these functions into the first order conditions and totally differentiating with respect to $t_{k}$ yields

$$
w_{k}^{\prime \prime}\left(t_{k}\right)=\frac{\partial^{2} p_{k}\left(v, t_{k}\right)}{\partial t_{k}^{2}}+\frac{\partial^{2} p_{k}\left(v, t_{k}\right)}{\partial t_{k} \partial v} v_{k}^{\prime}\left(t_{k}\right) .
$$

\footnotetext{
${ }^{10}$ Note $v_{1}^{\prime}<0$ and $v_{2}^{\prime}>0$. Functions $v_{i}, i=1,2$ play the same role as the function $h(g)$ in Sattinger (1975) p. 356, where $g$ is workers' ability (single scale) and $h(g)$ the difficulty (single scale) of the task performed by workers with ability $g$ in equilibrium and, $c(u)$ in Teulings (1995a, 1995b and 2005) where $u$ is the normalized level of skills and $c(u)$ the associated job complexity in equilibrium.

${ }^{11}$ Note that as long as the surplus of pairs of workers and firms is exhausted, i.e. the profits of a firm $v$ employing worker $t_{k}$ are $r(v)=p_{k}\left(v, t_{k}\right)-w_{k}\left(t_{k}\right)$, it is enough to study the firms' problem since the workers' problem yields the exact same solution by symmetry.
} 
Using Equation 5 yields

$$
-\frac{\partial^{2} p_{k}\left(v, t_{k}\right)}{\partial t_{k} \partial v} v_{k}^{\prime}\left(t_{k}\right)<0
$$

Hence, as long as the cross partial derivative $\frac{\partial^{2} p_{1}\left(v, t_{1}\right)}{\partial t_{1} \partial v}$ is negative and the cross partial derivative $\frac{\partial^{2} p_{2}\left(v, t_{2}\right)}{\partial t_{2} \partial v}$ is positive, i.e. as long as workers skills of type 1 (type 2) complement machines close to 0 (respectively 1 ) as stated in assumption $A$ iii), a competitive assignment is such that within skills groups more skilled workers get more productive machines, i.e. $v_{1}^{\prime}<0$ and $v_{2}^{\prime}>0$, which corresponds to the optimal assignment.

\subsection{Equilibrium}

\subsubsection{Definition}

Definition 1 A competitive equilibrium consists of 1) two wage functions $w_{k}\left(t_{k}\right)$ that indicate a worker's earnings associated with the level and type of skills this worker supplies and pin down the index function $t_{k}^{*}\left(t_{j}\right)=w_{k}^{-1}\left(w_{j}\left(t_{j}\right)\right)$ and hence the supply of skills $\xi_{k}\left(t_{k}\right)$, 2) a marginal task $\varepsilon$ that indicates the set of tasks assigned to workers of each type and 3) two mapping functions $v_{k}\left(t_{k}\right)$ that indicate the type of machine assigned to workers of each type and level of skills such that i) workers maximize earnings and firms maximize rents and ii) both the labor and capital markets clear.

The density of workers' skills is directly derived from the density of tasks by performing the transformation of variables $v=v_{k}\left(t_{k}\right)$ and noting that $d v_{k}=v_{k}^{\prime} \cdot d t_{k}$. This yields:

$$
\begin{aligned}
& \int_{0}^{\varepsilon} f(v) \cdot v_{1}^{\prime}\left(t_{1}\right) \cdot d t_{1}=\int_{0}^{\infty} \xi_{1}\left(t_{1}\right) \cdot d t_{1} \\
& \int_{\varepsilon}^{1} f(v) \cdot v_{2}^{\prime}\left(t_{2}\right) \cdot d t_{2}=\int_{0}^{\infty} \xi_{2}\left(t_{2}\right) \cdot d t_{2} .
\end{aligned}
$$

Hence, the following result:

Result R2: In equilibrium the density of workers with skills $t_{k}$ is

$$
\xi_{k}\left(t_{k}\right)=f\left(v_{k}\left(t_{k}\right)\right) \cdot v_{k}^{\prime}\left(t_{k}\right) .
$$


At first sight, these equations look like independent first order nonlinear nonautonomous differential equations ${ }^{12}$ However, since the distribution of skills is endogenous, $\xi_{j}\left(t_{j}\right)$ in Equation 8 depends on equilibrium wages through the index function $t_{k}^{*}\left(t_{j}\right)$. As is shown below, equilibrium wages are derived from the first order condition to profit maximization. This condition stipulates that wage differentials are set equal to productivity differentials. The wage functions are therefore obtained by integrating the productivity differentials evaluated at the equilibrium task, i.e. replacing $v$ by $v_{k}\left(t_{k}\right)$, over skills of the respective types. This means that each wage function depends not only on the shape of the production function of worker-task pairs for each type of workers but also on the associated mapping function. As a result, each $\xi_{j}\left(t_{j}\right)$ is a function of both mapping functions. Hence, $v_{1}\left(t_{1}\right)$ and $v_{2}\left(t_{2}\right)$ are solutions of a system of first order nonlinear nonautonomous differential equations.

The marginal task is then derived so that

$$
F(\varepsilon)=\int_{0}^{\infty} \xi_{1}\left(t_{1}\right) \cdot d t_{1}
$$

Evaluating the differential Equation 4 at $v=v_{k}\left(t_{k}\right)$ and integrating over $t_{k}$ yields the wage function for workers supplying skills of type $k$.

$$
w_{k}\left(t_{k}\right)=w_{k 0}+\int_{t_{k, \varepsilon}}^{t_{k}}\left[\frac{\partial p_{k}(v, x)}{\partial x}\right]_{v=v_{k}(x)} d x
$$

where $w_{k 0}$ is a constant of integration.

The wage functions are identified up to constants of integration. Following Sattinger (1979) ${ }^{13}$ the model is closed by specifying exogenous reserve prices for the marginal workers and machine. For the least skilled workers in both groups to be indifferent between being assigned to machine $\varepsilon$ or remaining unemployed we need $\min _{k} w_{k 0}=\widetilde{w}$ where $\widetilde{w}>0$ is the reservation wage. Since firms owning machines $\varepsilon$ are indifferent between employing the least skilled worker of each type, it follows that $r_{\varepsilon}=p_{k}\left(\varepsilon, t_{k, \varepsilon}\right)-w_{k 0} k=1,2$

\footnotetext{
${ }^{12}$ In the one dimensional skill case with both the distribution of skills and tasks being exogenous, as in Sattinger (1979 and 1993), equation 8 is indeed a first order nonlinear nonautonomous differential equation that admits closed form solutions when tasks and skills follow a Pareto or a Normal distribution.

${ }^{13}$ Costrell and Loury (2004) consider a continuum of tasks in a single enterprise, not in the whole economy, and therefore close the model by a free entry condition that drives profits of each enterprise down to 0.
} 
$\forall \varepsilon$. Furthermore, for the firms owning machines $\varepsilon$ to be indifferent between supplying the machine to the market or withholding the machine from the market we need $r_{\varepsilon}=\widetilde{r}$ where $\widetilde{r} \geq 0$ is the reserve price for the owner of capital. Let $w_{i 0}=\min _{k} w_{k 0}=\widetilde{w}$. One obtains

$$
\begin{aligned}
& p_{i}\left(\varepsilon, t_{i, \varepsilon}\right)=\widetilde{w}+\widetilde{r} \\
& p_{j}\left(\varepsilon, t_{j, \varepsilon}\right)=w_{j 0}+\widetilde{r}
\end{aligned}
$$

where by definition, $p_{j}\left(\varepsilon, t_{j, \varepsilon}\right)-p_{i}\left(\varepsilon, t_{i, \varepsilon}\right)=w_{j 0}-\widetilde{w} \geq 0$.

The inverse functions $q_{k}(\varepsilon,)=.p_{k}^{-1}(\varepsilon,) k=1,$.2 are well defined and strictly increasing in the second argument given Assumption A ii). One obtains the lowest levels of skills of each type supplied in the economy given wage constants $w_{k 0} k=1,2$ and the marginal task $\varepsilon$ as

$$
\begin{aligned}
t_{i, \varepsilon} & =q_{i}(\varepsilon, \widetilde{w}+\widetilde{r}) \\
t_{j, \varepsilon} & =q_{j}\left(\varepsilon, w_{j 0}+\widetilde{r}\right) .
\end{aligned}
$$

Workers' self-selection and the assignment of skills to tasks is depicted in Figures 2 and 3 . Figure 2 features an economy where both types of skills are positively correlated in the population whereas Figure 3 shows an economy where both types are negatively correlated. The upward sloping line corresponds to the selection curve $t_{2}^{*}\left(t_{1}\right)$. This line slants the bivariate distribution in 2 regions. Above the line, workers supply their skills of type 2 while below workers supply type 1 skills. Workers with the lowest level of each skills are assigned to the marginal task $\varepsilon$ while workers with the highest level of type 1 are assigned to task 0 and workers with the highest level of type 2 are assigned to task 1.

The equilibrium distribution of wages within skills groups is readily obtained from the equilibrium distribution of skills within skills groups. To see this, let $\Theta_{t_{k}}\left(t_{k}\right) \equiv \frac{\int_{t_{k, \varepsilon}}^{t_{k}} \xi_{k}(x) d x}{\int_{t_{k, \varepsilon}}^{\infty} \xi_{k}(x) d x}$ be the equilibrium CDF of $t_{k}$. Then, $t_{k}(\mu) \equiv \Theta_{t_{k}}^{-1}(\mu)$ for $\mu \in[0,1]$ is the quantile function of the equilibrium distribution of skills of type $k$. Since equilibrium wages are strictly monotonic in $t_{k}$ from result $\mathrm{R} 1$, we then have that $w_{k}\left(t_{k}(\mu)\right)$ defines the quantile function of the equilibrium distribution of wages for skills of type $k$. In words, if a share $\mu$ of workers supplying type $k$ skills has skills level lower than $t_{k}(\mu)$ then there is a share $\mu$ of workers supplying skills of type $k$ with wages lower than $w_{k}\left(t_{k}(\mu)\right)$. Within skills groups, the wage gap between the $\mu^{+}$th and $\mu^{-}$th quantiles is then simply expressed as $G_{k}\left(\mu^{+}, \mu^{-}\right) \equiv$ $w_{k}\left(t_{k}\left(\mu^{+}\right)\right)-w_{k}\left(t_{k}\left(\mu^{-}\right)\right)$. The between group wage gap at the $\mu$ th quantile can be expressed as $B_{12}(\mu) \equiv w_{1}\left(t_{1}(\mu)\right)-w_{2}\left(t_{2}(\mu)\right)$. 


\subsubsection{Existence of an equilibrium}

The equilibrium in the economy depicted above is such that:

1. The supply density of skills of type $k$ is given as

$$
\xi_{k}\left(t_{k}\right)=\int_{0}^{w_{j}^{-1}\left(w_{j}\left(t_{k}\right)\right)} \xi\left(t_{j}, t_{k}\right) d t_{j}
$$

2. The wages of type $k$ skills are given as

$$
w_{k}\left(t_{k}\right)=w_{k 0}+\int_{t_{k, \varepsilon}}^{t_{k}}\left[\frac{\partial p_{k}(v, x)}{\partial x}\right]_{v=v_{k}(x)} d x
$$

3. The mapping of type $k$ workers to tasks is given as the solution to

$$
f\left(v_{k}\left(t_{k}\right)\right) v_{k}^{\prime}\left(t_{k}\right)=\xi_{k}\left(t_{k}\right) .
$$

These 3 key results suggest the following Gauss-Seidel algorithm to solve for $w_{k}(),. v_{k}($.$) and hence \xi_{k}($.$) given the primitives p_{k}(.,),. f($.$) and \xi(.,$.$) :$

1. Guess an initial pair of functions $\left(\xi_{1}^{i}(),. \xi_{2}^{i}().\right) \in \Gamma(\xi(.,)$.$) where \Gamma(\xi(.,)$. is the set of feasible truncated densities given $\xi(.,$.$) .14$

2. Given $\left(\xi_{1}^{i}(),. \xi_{2}^{i}().\right)$, solve for $\left(v_{1}^{i}(),. v_{2}^{i}().\right)$ using Equation 13

3. Plug $\left(v_{1}^{i}(),. v_{2}^{i}().\right)$ into Equation 12 to obtain $\left(w_{1}^{i}(),. w_{2}^{i}().\right)$.

4. Plug $\left(w_{1}^{i}(),. w_{2}^{i}().\right)$ into Equation 11 and solve for $\left(\xi_{1}^{i+1}(),. \xi_{2}^{i+1}().\right)$.

5. Go back to (2) replacing $i$ by $i+1$ and repeat (2)-(5) until convergence.

It is important to note that the truncated densities obtained from step 4 are necessarily such that $\left(\xi_{1}^{i+1}(),. \xi_{2}^{i+1}().\right) \in \Gamma(\xi(.,)$.$) since they are gen-$ erated using Equation 11. The algorithm therefore maps $\left(\xi_{1}^{i}(),. \xi_{k}^{i}().\right) \in$ $\Gamma(\xi(.,)$.$) onto \left(\xi_{1}^{i+1}(),. \xi_{2}^{i+1}().\right) \in \Gamma(\xi(.,)$.$) and Kakutani-Glicksberg-Fan's$ fixed point theorem gives us the following existence theorem:

Theorem 2 A competitive equilibrium $\left(w_{k}(.), v_{k}(.), \xi_{k}(.)\right)_{k=1,2}$ exists in this economy.

\footnotetext{
${ }^{14} \mathrm{An}$ easy way to proceed is to set initial wage functions; for instance, letting $w_{1}^{i}\left(t_{1}\right)=$ $w_{2}^{i}\left(t_{2}\right)$ such that $t_{k}^{i *}\left(t_{j}\right)=t_{j}$. Plugging this selection curve into Equation 11 obtains $\left(\xi_{1}^{i}(),. \xi_{2}^{i}().\right) \in \Gamma(\xi(.,)$.$) .$
} 
Proof. The set $\Gamma(\xi(.,)$.$) is non-empty, compact and convex. Moreover,$ the map $M: \Gamma(\xi(.,).) \rightarrow \Gamma(\xi(.,)$.$) defined by an iteration of the algo-$ rithm is upper semicontinuous, and $M\left(\left(\xi_{1}(),. \xi_{2}().\right)\right)$ is non-empty, compact and convex for all $\left(\xi_{1}(),. \xi_{2}().\right) \in \Gamma(\xi(.,)$.$) . M$ is therefore a Kakutani map such that the Kakutani-Glicksberg-Fan's fixed point theorem applies: $M$ has a fixed point $\left(\xi_{1}(),. \xi_{2}().\right)=M\left(\xi_{1}(),. \xi_{2}().\right)$. A sequence $\left(\xi_{1}^{i}(.), \xi_{2}^{i}(.)\right)_{i=1}^{n} \in \Gamma(\xi(.,)$.$) generated by the algorithm above converges to$ a solution $\left(\xi_{1}(),. \xi_{2}().\right) \in \Gamma(\xi(.,)$.$) as n \rightarrow \infty$.

Since the sequence $\left(\xi_{1}^{i}(.), \xi_{2}^{i}(.)\right)_{i=1}^{n} \in \Gamma(\xi(.,)$.$) converges, so do the se-$ quences $\left(w_{1}^{i}(.), w_{2}^{i}(.)\right)_{i=1}^{n}$ and $\left(v_{1}^{i}(.), v_{2}^{i}(.)\right)_{i=1}^{n}$ generated along by the algorithm. We conclude that

$$
\lim _{n \rightarrow \infty}\left(\left(w_{k}^{i}(.), v_{k}^{i}(.), \xi_{k}^{i}(.)\right)_{k=1,2}\right)_{i=1}^{n}=\left(w_{k}(.), v_{k}(.), \xi_{k}(.)\right)_{k=1,2}
$$

which proves the existence of a competitive equilibrium.

\section{Technological change and self-selection}

In this section, the objective is to use predictions of the model to understand the role of endogenous supply of skills in the observed evolution of the US wage distribution as presented in Figure 1. The algorithm presented above turns out to be extremely helpful. To see this, suppose that at time $t$ the economy is in equilibrium at $w_{k}()=.w_{k}^{t}(),. v_{k}()=.v_{k}^{t}($.$) and \xi_{k}()=.\xi_{k}^{t}($. for $p_{k}(.,)=.p_{k}^{t}(.,),. f()=.f^{t}($.$) and \xi(.,)=.\xi^{t}(.,$.$) .$

Consider a technical change that takes place between $t$ and $t+1$. In particular, assume that this technical change takes the following simple form: ${ }^{15}$

$$
\begin{aligned}
& p_{1}^{t+1}(., .)=\left\{\cdot \chi_{1} p_{1}^{t}(., .) \text { if } v<\varepsilon^{t} p_{1}^{t}(., .)\right. \text { else } \\
& p_{2}^{t+1}(., .)=\left\{\cdot \chi_{2} p_{2}^{t}(., .) \text { if } v>\varepsilon^{t} p_{2}^{t}(., .)\right. \text { else. }
\end{aligned}
$$

This technical change affects the productivity of each group of workers only in tasks that each group was respectively assigned to at $t$. Using Johnson's (1997) terminology, the technical change depicted in Equation 14 is an intensive technical change.

For the sake of the argument, suppose that skills of type 1 are manual skills and skills of type 2 are intellectual skills. The empirical literature (see

\footnotetext{
${ }^{15}$ All the results of this section would still hold if one chose the less restrictive type of technical change: $p_{k}^{t+1}=\chi_{k} p_{k}^{t}(.,$.$) for all v$. The motivation for choosing specification in Equation 14 is to make the point that an intensive SBTC necessarily leads to an extensive SBTC when skills supply is endogenous.
} 
Acemoglu and Autor, 2011 for an excellent review and exposition) has shown evidence that the technical changes that took place in the last 6 decades have been biased in favor of more skills and relatively more so for intellectual skills. Keeping in mind our objective, it seems therefore reasonable to restrict ourselves to cases where $\chi_{2} \geq \chi_{1} \geq 1$.

Let us separate the total impact of this SBTC on wages into two distinct effects:

1. the productivity effect corresponding to the change in the structure of wages resulting from a SBTC at constant supply of skills and,

2. the composition effect corresponding to the additional effect of this SBCT on the structure of wages coming from the endogenous change in workers' supply of skills.

\section{The productivity effect}

Suppose first that the supply of skills were exogenous and constant in the economy such that $\xi_{k}^{t+1}()=.\xi_{k}^{t}($.$) . The task of comparing the distribution$ of wages before and after the technical change would then be simplified considerably by this assumption since one would have that $\Theta_{t_{k}}^{t+1}\left(t_{k}\right)=\Theta_{t_{k}}^{t}\left(t_{k}\right)$ and therefore $t_{k}^{t+1}(\mu)=t_{k}^{t}(\mu)$ for $k=1,2$. As a result, one would then simply have $v_{k}^{t+1}()=.v_{k}^{t}($.$) by virtue of Equation 13$. Note that the algorithm presented above simplifies considerably in this case: one just has to apply step 2 and step 3 once to achieve equilibrium.

Given exogenous and constant supply of skills, the only consequence of this technical change on equilibrium would be to alter the slope of the equilibrium wage functions via equation 12 , In particular, one would have

$$
\begin{aligned}
w_{k}^{t+1}\left(t_{k}(\mu)\right)-w_{k 0}^{t+1} & =\int_{t_{k, \varepsilon}}^{t_{k}(\mu)}\left[\frac{\partial p_{k}^{t+1}(v, x)}{\partial x}\right]_{v=v_{k}(x)} d x \\
& =\chi_{k} \int_{t_{k, \varepsilon}}^{t_{k}(\mu)}\left[\frac{\partial p_{k}^{t}(v, x)}{\partial x}\right]_{v=v_{k}(x)} d x \\
& =\chi_{k}\left(w_{k}^{t}\left(t_{k}(\mu)\right)-w_{k 0}^{t}\right)
\end{aligned}
$$

As a result, within skills groups, wages at all quantiles would increase when $\chi_{k}>1$ except for the minimum wages that remain constant, i.e. $w_{k 0}^{t+1}=$ $w_{k 0}^{t}=w_{k 0}$. Using Equation 15 and assuming that $\left.w_{10}=w_{20}=\widetilde{w}\right]^{16}$ one

\footnotetext{
${ }^{16}$ In the data, one always find a significant number of college and high-school graduates working at the minimum wage $\widetilde{w}$ such that this assumtpion has no bite in our exercise.
} 
can derive measures of changes in inequality both between and within skills groups. The change in the between group wage gap (at the median) then reads as

$$
B_{12}^{t+1}(0.5)-B_{12}^{t}(0.5)=\left(\chi_{1}-1\right) B_{12}^{t}(0.5)+\left(\chi_{1}-\chi_{2}\right)\left(w_{2}^{t}\left(t_{2}(0.5)\right)-\widetilde{w}\right) .
$$

The following proposition holds.

Proposition 3 Given that $\chi_{2} \geq \chi_{1} \geq 1$ and $w_{10}=w_{20}=\widetilde{w}$, an economy with $B_{12}^{t}<0$ will have $B_{12}^{t+1} \leq B_{12}^{t}<0$ unless $\chi_{1}=\chi_{2}=1$.

Proof. By simple inspection of Equation 16, one notes that the two terms on the right hand side are negative given $\chi_{2} \geq \chi_{1} \geq 1$ and $B_{12}^{t}<0$.

Proxying the median wage of intellectual workers by that of college graduates and that of manual workers by high-school workers, empirical evidence for the US shows that $B_{12}(0.5)<0$ since at least 1963 (see Figure 1). Therefore, for $\chi_{2} \geq \chi_{1}>1$, Proposition 3 indicates that $B_{12}^{t+1}(0.5) \leq B_{12}^{t}(0.5)<0$, such that the median wage for intellectual skills rises relative to that of manual skills after the technical change.

Within skills groups, the wage gap between quantile $\mu^{+}$and $\mu^{-}$at $t+1$ obtains as

$$
G_{k}^{t+1}\left(\mu^{+}, \mu^{-}\right)=\chi_{k} G_{k}^{t}\left(\mu^{+}, \mu^{-}\right),
$$

and, given that $\chi_{2} \geq \chi_{1} \geq 1$, we conclude that at constant supply of skills, within skills group wage inequality increases everywhere in the distribution.

The question arises as: can the between wage inequality remain stable while the within wage inequality increases in both skills groups following a technical change of the form given in Equation 14? The answer is simply no at sight of Proposition 3 as long as the supply of skills remains constant. For the within group wage inequality to rise requires $\chi_{2} \geq \chi_{1}>1$ whereas for the between wage gap to remain stable at constant supply requires $\chi_{1}=\chi_{2}=1$.

This simple example highlights the role of supply in generating the data observed in Figure 1. Compare the wage distribution in 1965 and 1980. The between wage gap is similar in both years but the within wage inequality is larger in 1980 in both groups. The model predicts that this could only happen as a result of technical change if the supply of intellectual skills (college graduates) increased at the same time.

Evidence shows that the supply of college graduates has indeed increase between 1965 and 1980. The question arises: how much of this increase in the supply of intellectual skills has been generated endogenously by the 
technical change through workers' self-selection? In other words, what are the sign and magnitude of the composition effect?

\section{The composition effect}

To answer this question, consider the algorithm presented above and let us follow the adjustment process that would occur as a result of a technical change with $\chi_{2} \geq \chi_{1}>1$. Let $t_{2}^{*(t)}\left(t_{1}\right) \equiv w_{2}^{t}\left(w_{1}^{t}\left(t_{1}\right)\right)^{-1}$ and $\varepsilon^{(t)}$ denote respectively the self-selection curve, determining the supply of skills, and the marginal task at the initial assignment equilibrium.

Start from Equation 12, and note that, at constant assignment of skills to tasks, the technical change would alter this equation resulting in

$$
w_{k}^{t, 1}\left(t_{k}\right)=w_{k 0}+\chi_{k}\left(w_{k}^{t}\left(t_{k}\right)-w_{k 0}\right) .
$$

Using this result, one obtains the new self-selection curve as:

$$
t_{2}^{*(t, 1)}\left(t_{1}\right)=w_{2}^{t}\left(\left(1-\frac{\chi_{1}}{\chi_{2}}\right) w_{10}+\frac{\chi_{1}}{\chi_{2}} w_{1}^{t}\left(t_{1}\right)\right)^{-1} .
$$

For $\chi_{2} \geq \chi_{1} \geq 1$, and since $w_{2}^{t}($.$) is strictly increasing from result R1,$ one directly observes that the term $\left(1-\frac{\chi_{1}}{\chi_{2}}\right) w_{10} \geq 0$ shifts the new selfselection curve to the left of the initial self-selection curve whereas the factor $0<\frac{\chi_{1}}{\chi_{2}} \leq 1$ decreases the slope of the new selection curve relative to that of the initial curve. In fact, one can prove that for $0 \leq \frac{\chi_{1}}{\chi_{2}}<1$, there is a unique point of invariance in the selection curve.

Lemma 4 When $0 \leq \frac{\chi_{1}}{\chi_{2}}<1$, the selection curve rotates clockwise in the $\left(t_{1}, t_{2}\right)$ plan. The center of rotation is $\left(t_{1, \varepsilon^{(t)}}, t_{2}^{*(t)}\left(t_{1, \varepsilon^{(t)}}\right)\right)$.

Proof. Let $T=\left(\left(t_{1}, t_{2}\right) \in \mathbb{R}_{+}^{2} \mid t_{2}=t_{2}^{*(t, 1)}\left(t_{1}\right)=t_{2}^{*(t)}\left(t_{1}\right)\right)$ be the set of invariant points of the selection curve. These points satisfy conditions of the type

$$
h(k)=h(a+b k)
$$

where $h=w_{2}^{-1}, k=w_{1}\left(t_{1}\right), a=\left(1-\frac{\chi_{1}}{\chi_{2}}\right) w_{k 0}$ and $b=\frac{\chi_{1}}{\chi_{2}}$. Note that $h$ is strictly increasing in $k, a \geq 0$ and $b \in[0,1)$.

For $b \in[0,1)$, we have $T=\left\{\left(t_{1, \varepsilon}^{(t)}, t_{2}^{*(t)}\left(t_{1, \varepsilon}^{(t)}\right)\right)\right\}$ since the condition requires $k=\frac{a}{1-b}$ and hence $w_{1}\left(t_{1}\right)=w_{10}$ which is only true for $t_{1}=t_{1, \varepsilon}^{(t)}$. One 
then concludes that there is a unique point of invariance: $\left(t_{1, \varepsilon}^{(t)}, t_{2}^{*(t)}\left(t_{1, \varepsilon}^{(t)}\right)\right)$ which defines the center of rotation of the selection curve.

This lemma is depicted in Figures 4, 5, 6 and 7for linear selection curves. The full lines represent the initial selection line $t_{2}^{*(t)}\left(t_{1}\right)$ whereas the dotted line represent the new selection line $t_{2}^{*(t, 1)}\left(t_{1}\right)$. Figures 4 and 5 consider the case where manual and intellectual skills are positively correlated in the population whereas Figures 6 and 7 depict the case where skills are negatively correlated.

Let us first consider the case where skills are positively correlated. Figure 4 (respectively Figure 5) shows the impact of SBTC on the supply of skills at constant assignment of skills to tasks when manual skills are relatively less (more) concentrated in the population. As expected, in both situations, some individuals are willing to switch from supplying manual skills to supplying intellectual skills. Call these workers "switchers". In both situations, "switchers" tend to have relatively high manual skills compared to those still supplying their manual skills. Hence the median manual skills supplied in the economy decreases and so does the median wage of manual workers compared to that resulting at constant supply of skills.

When manual skills are relatively more concentrated (Figure 5), compared to individuals already supplying intellectual skills, "switchers" tend to have relatively low intellectual skills, such that the median intellectual skills supplied decreases and so does the median wage of intellectual workers compared to that resulting at constant supply of skills. However, when manual skills tend to be less concentrated (Figure 4), "switchers" tend to have relatively high intellectual skills. Hence the median intellectual skills supplied increases and so does the median wage of intellectual workers compared to that resulting at constant supply of skills.

As a result, when skills are positively correlated, for any SBTC of the form given in Equation 14, that is for any given productivity effect, the composition effect will be large and positive when manual skills are less concentrated but close to zero otherwise.

Consider now the case where skills are negatively correlated. Figure 6 (respectively Figure 7) shows the impact of SBTC on the supply of skills at constant assignment of skills to tasks when manual skills are relatively less (more) concentrated in the population. In both situations, compared to individuals already supplying intellectual skills, "switchers" tend to have low intellectual skills. Hence, the median intellectual skills supplied decreases and so does the median wage of workers supplying intellectual skills compared to that resulting at constant supply of skills.

When manual skills are less concentrated (Figure 6p), "switchers" tend 
to have relatively low manual skills compare to those still supplying manual skills. The median manual skills supplied increases and so does the median wage of workers supplying manual skills compared to that resulting at constant supply of skills. In contrast, when manual skills are more concentrated (Figure 6), "switchers" tend to have relatively high manual skills compared to those still supplying manual skills. The median manual skills supplied decreases and so does the median wage of workers supplying manual skills compared to that resulting at constant supply of skills.

As a result, when skills are negatively correlated, for any SBTC of the form given in Equation 14, i.e. for any given productivity effect, the composition effect will be large and negative when manual skills are relatively less concentrated but close to zero otherwise.

These examples clearly emphasize the crucial role played by the population distribution in understanding the impact of SBTC on the structure of wages. If skills are positively correlated in the population and manual skills are relatively less concentrated, the observed between wage inequality overestimates the true productivity effect of SBTC as the composition effect is large and positive. In contrast, if skills are negatively correlated and manual skills are relatively less concentrated then the observed between wage inequality underestimates the true productivity effect of SBTC as the composition effect is large and negative. We conclude that knowing the correlation between skills types and their relative concentration (variance) is therefore of crucial importance to infer the magnitude of SBTC from wage data.

Let us formalize these results by assuming, as in the graphical illustrations above, that the equilibrium wage functions are linear: $w_{i}\left(t_{i}\right)=w_{i 0}+a_{i} t_{i}$ with $a_{i}>0$ for $i=1,2$. By the law of iterative expectations one has

$$
P_{2} E_{22}+\left(1-P_{2}\right) E_{21}=\mu_{2}
$$

where $P_{2}=\operatorname{Pr}\left[w_{2}>w_{1}\right], E_{i j}=E\left[t_{i} \mid w_{j}>w_{i}\right]$ and $E\left[t_{i}\right]=\mu_{i}$.

Rearranging yields

$$
P_{2} R_{22}+\left(1-P_{2}\right) R_{21}=0
$$

where $R_{i j}=E_{i j}-\mu_{i}$.

Intuitively, $R_{i i}$ indicates the amount of selection in equilibrium for skills of type $i$ : if $R_{i i}>0$ there is positive selection such that those workers supplying type $i$ skills in equilibrium tend to have relatively high levels of these skills whereas if $R_{i i}<0$ there is negative selection. This simple framework can be used to corroborate all of the graphical results above but let us for instance consider the case where positive sorting for intellectual skills arises. One then has: $R_{22}>0$ and $R_{21}<0$. For instance, when skills are Normally 
distributed, positive selection for skills of type 2 arises when the skills of type 2 are relatively less concentrated than the skills of type 1.17

Note that in this setting, a SBTC of the form given in Equation 14 would rise the slope of the wage function for intellectual skills $a_{2}$, relative to the slope of the wage function for manual skills $a_{1}{ }^{18}$ Assume for simplicity that $a_{1}$ remains constant. Obviously, an increase in $a_{2}$ will increase $P_{2}$ by say $\epsilon>0$ such that if $R_{22}$ and $R_{21}$ were unchanged one would have

$$
\left(P_{2}+\epsilon\right) R_{22}+\left(1-P_{2}-\epsilon\right) R_{21}>0
$$

It follows that $R_{22}$ must decrease and $R_{21}$ must increase to restore the equality in Equation (17) given the higher value of $a_{2}$. As a result, when $a_{2}$ increases, the mean intellectual skills of workers supplying intellectual skills in equilibrium decreases when there is positive sorting on intellectual skills. This corroborates the result of the graphical analysis above: the mean intellectual skills supplied will decrease when skills are positively correlated $\left(r_{12}>0\right)$ and manual skills are relatively more concentrated $\left(V_{1}\right.$ is relatively small compared to $V_{2}$ ). Similar conditions can be derived that will corroborate all results of the graphical analysis above.

A remaining interesting question arises: can we distinguish between an extensive SBTC and an intensive SBTC from data on tasks assignment? The answer is simply no. The SBTC considered in this section is clearly an intensive SBTC. However, as shown above, following this SBTC, more workers are supplying intellectual skills. This implies that the marginal task will have to shift to the left by inspection of Equation 9. We therefore have: $\varepsilon^{(t)}>\varepsilon^{(t, 1)}$ where $\varepsilon^{(t)}$ is the marginal task at period $t$ and $\varepsilon^{(t, 1)}$ the marginal task given the supply of skills derived at constant assignment of skills to tasks. This means that some workers supplying intellectual skills, i.e. those with the lowest level of intellectual skills, will be assigned to tasks

\footnotetext{
${ }^{17}$ Let skills follow a bivariate Gaussian distribution. Denote $V_{i}=\operatorname{Var}\left(t_{i}\right)$ for $i=1,2$, $V_{12}=C O V\left(t_{1}, t_{2}\right)$ and $r_{12}=\frac{V_{12}}{\sqrt{V_{1} V_{2}}} \in[-1,1]$. With these restrictions, the first moments $E\left[t_{i} \mid w_{i}\left(t_{i}\right) \geq w_{j}\left(t_{j}\right)\right]$ have known expressions and one has

$$
\begin{aligned}
R_{22} & \equiv E\left[t_{2} \mid w_{2}\left(t_{2}\right) \geq w_{1}\left(t_{1}\right)\right]-E\left[t_{2}\right] \\
& =\frac{\tau_{2}}{\sigma} \lambda\left(s_{2}\right)
\end{aligned}
$$

where $\tau_{2}=a_{2}^{2} V_{2}-a_{1} a_{2} V_{12}, \sigma=\left(a_{1}^{2} V_{1}+a_{2}^{2} V_{2}-2 a_{1} a_{2} V_{12}\right)^{1 / 2}, s_{2}=\frac{w_{20}-w_{10}+a_{2} E\left[t_{2}\right]-a_{1} E\left[t_{1}\right]}{\sigma}$ and $\lambda()=\frac{\varphi()}{\Phi()}$ where $\varphi$ and $\Phi$ are respectively the p.d.f. and c.d.f. of the strandard Gaussian distribution and with $\lambda()>0$ and $\lambda^{\prime}() \leq 0$. There is positive selection for intellectual skills if and only if $\left(\frac{V_{2}}{V_{1}}\right)^{1 / 2}>\frac{a_{1}}{a_{2}} V_{12}$.

${ }^{18}$ Noting $w_{i}^{(t)}\left(t_{i}\right)=w_{i 0}+a_{i} t_{i}$ one would have $w_{i}^{(t, 1)}\left(t_{i}\right)=w_{i 0}+\chi_{i} a_{i} t_{i}$ with $\chi_{2} \geq \chi_{1} \geq 1$.
} 
in the range $\left(\varepsilon^{(t, 1)}, \varepsilon^{(t)}\right)$. These tasks were initially performed by workers supplying manual skills. Even though the technical change given in Equation 9 is intensive in nature, endogenous supply of skills necessarily leads to a reassignment of tasks across skills groups just as in Jonhson's (1997) extensive SBTC. In an economy where workers can respond to SBTC by changing the type of skills they supply, an intensive SBTC would generally lead to a reassignment of tasks to types of skills; there is no need for the SBTC to be extensive in nature. This is important because it means that the true nature of SBTC is not identified from data on tasks assignment.

\section{Discussion}

This paper contributed to the literature on assignment models of workers to tasks by presenting a general equilibrium assignment model with endogenous distribution of skills. The distribution of skills is endogenized through workers' self-selection of the type of skills they supply. This self-selection can take the form of human capital formation via educational self-selection. The main characteristic of this model is that two types of assignment occur. The first type of assignment is workers' selection of the type of skills to supply. Under mild conditions, spelled out in Assumption $B$, workers specialize and supply their skills of the type that maximizes their earnings. The second type of assignment is the assignment of workers to tasks. Each task is associated with a unit of capital, a machine for the sake of the argument, and the various tasks correspond to machines with different characteristics. To produce output, each machine needs to be operated by one and only one worker. Although the various machines can be operated by workers with different types and levels of skills, workers of different types and levels of skills differ in their productivity. I show that if the productivity of worker-task pairs satisfies assumption $A$ then, following Ricardo's principles of comparative advantage and differential rents, equilibrium in this model is characterized by two mapping functions, one for each type of skills supplied. The first mapping function is decreasing and maps skills of the first type to tasks on the left hand side of the support. The second mapping function is increasing and maps skills of the other type to tasks on the right hand side of the support. These two mapping functions generate two wage functions, one for each type of skills, that will generally overlap. The existence of an equilibrium in this economy is proved and an algorithm to find a numerical solution is provided.

The model presented in this paper offers a new framework to study the impact of technical change on the structure of wages. As in standard unidimensional assignment models, the model presented in this paper enables 
us to distinguish between the contribution of human factors and the contribution of technical factors in rising wage inequality. In contrast to existing assignment models, the model presented in this paper endogenizes the distribution of skills. This model therefore allows us to decompose the total impact of SBTC on wage inequality into a productivity effect (at constant supply) and a composition effect due to the impact of SBTC on the supply of skills.

Qualitative analyses highlight two important results. First, the population distribution of skills plays a crucial role in understanding the impact of SBTC on the structure of wages. If skills are positively correlated in the population and manual skills are relatively less concentrated, the observed between wage inequality overestimates the true productivity effect of SBTC as the composition effect is large and positive. In contrast, if skills are negatively correlated and manual skills are relatively less concentrated then the observed between wage inequality underestimates the true productivity effect of SBTC as the composition effect is large and negative.

Second, in an economy where workers can respond to SBTC by changing the type of skills they supply on the labor market, an intensive SBTC would generally lead to a reassignment of tasks to types of skills. This means that it is impossible to distinguish between intensive and extensive SBTC from data on tasks assignment alone.

\section{References}

Acemoglu, D. (2002): "Technical Change, Inequality and the Labor Market," Journal of Economic Literature, 40(1), 7-72.

Acemoglu, D., And D. Autor (2011): Skills, Tasks and Technologies: Implications for Employment and Earningsvol. 4 of Handbook of Labor Economics, chap. 12, pp. 1043-1171. Elsevier.

Autor, D. H., L. F. Katz, and M. S. Kearney (2006): "The Polarization of the U.S. Labor Market," American Economic Review, 96(2), 189-94.

Bertrand, M., and A. Schoar (2003): "Managing With Style: The Effect Of Managers On Firm Policies," The Quarterly Journal of Economics, 118(4), 1169-1208.

Bloom, N., And J. V. Reenen (2007): "Measuring and Explaining Management Practices Across Firms and Countries," The Quarterly Journal of Economics, 122(4), 1351-1408. 
Candelon, B., And A. Dupuy (2012): "Hierarchical Organization and Performance Inequality: Evidence from Professional Cycling," Working Papers 2012/12, Maastricht School of Management.

Costrell, R. M., And G. C. Loury (2004): "Distribution of Ability and Earnings in a Hierarchical Job Assignment Model," Journal of Political Economy, 112(6), 1322-1363.

CRIFO, P. (2008): "Skill supply and biased technical change," Labour Economics, 15(5), 812-830.

Dupuy, A. (2008): "The Assignment of Workers to Tasks, Wage Distribution and Technical Change: A Critical Review," Journal of Income Distribution, 17(3).

EicheR, T. S. (1996): "Interaction between Endogenous Human Capital and Technological Change," Review of Economic Studies, 63(1), 127-44.

Epple, D., R. Romano, and H. Sieg (2006): "Admission, Tuition, and Financial Aid Policies in the Market for Higher Education," Econometrica, 74(4), 885-928.

Gabaix, X., And A. Landier (2008): "Why Has CEO Pay Increased So Much?," The Quarterly Journal of Economics, 123(1), 49-100.

Garicano, L., and E. Rossi-Hansberg (2006): "Organization and Inequality in a Knowledge Economy," The Quarterly Journal of Economics, 121(4), 1383-1435.

Goos, M., And A. Manning (2007): "Lousy and Lovely Jobs: The Rising Polarization of Work in Britain," The Review of Economics and Statistics, 89(1), 118-133.

Johnson, G. (1997): "Changes in Earnings Inequality: The Role of Demand Shifts," Journal of Economic Perspectives, 11(2), 41-54.

Katz, L., And K. Murphy (1992): "Changes in Relative Wages, 19631987: Supply and Demand Factors," Quarterly Journal of Economics, 107(1), 35-78.

LAzEAR, E. P. (2005): "Entrepreneurship," Journal of Labor Economics, 25(4760), 649-80.

LucAs, R. E. (1978): "On the Size Distribution of Business Firms," Bell Journal of Economics, 9(2), 508-523. 
Rosen, S. (1982): "Authority, Control, and the Distribution of Earnings," Bell Journal of Economics, 13(2), 311-323.

Roy, A. (1950): "The Distribution of Earnings and of Individual Output," Economic Journal, 60(3), 489-505.

(1951): "Some Thoughts on the Distribution of Earnings," Oxford Economic Papers, 3(2), 135-46.

Sattinger, M. (1975): "Comparative Advantage and the Distribution of Earnings and Abilities," Econometrica, 43(3), 455-68.

(1978): "Comparative Advantage in Individuals," Review of Economics and Statistics, 60(2), 259-67.

(1979): "Differential Rents and the Distribution of Earnings," $O x$ ford Economic Papers, 31(1), 60-71.

(1980): Capital and the Distribution of Labor Earnings. Amsterdam: North-Holland.

(1993): "Assignment Models of the Distribution of Earnings," Journal of Economic Literature, 31(2), 831-80.

Tervio, M. (2008): "The Difference That CEOs Make: An Assignment Model Approach," American Economic Review, 98(3), 642-68.

Teulings, C. (1995a): "A Generalized Assignment Model of Workers to Jobs for the U.S. Economy," Tinbergen Institute, Discussion Paper, TI 95-67,.

(1995b): "The Wage Distribution in a Model of the Assignment of Skills to Jobs," Journal of Political Economy, 103(2), 180-215.

(2005): "Comparative Advantage, Relative Wages, and the Accumulation of Human Capital," Journal of Political Economy, 113(2), 42561.

Topel, R. H. (1997): "Factor Proportions and Relative Wages: The Supply-Side Determinants of Wage Inequality," Journal of Economic Perspectives, 11(2), 55-74.

Willis, R., And S. Rosen (1979): "Education and Self-Selection," Journal of Political Economy, 87(5), S7-S36. 


\section{Appendix}

Figure 1 is produced using the 1966, 1981, 1996 and 2005 CPS March supplements. Since the model studies educational choice college drop outs are herewith classified with college graduates for they chose to go to college. Workers working less than 38 hours and less than 39 weeks were excluded as well as self-employed. Furthermore, each year sample includes only white males aged between 18 and 65 and all observations missing crucial information on wages, hours, weeks worked, education, industry and occupation are deleted.

The wage measure used is the hourly earnings of full-time full-weeks workers defined as the annual earnings divided by total weeks worked and total hours worked 19 The hourly earnings are then deflated by the CPI-U (the Consumer Price Index for All Urban Consumers provided by the US department of Labor), to obtain a measure of real hourly earnings in 1996 US dollars.

As Katz and Murphy (1992), I excluded workers with real hourly earnings below one half of the real minimum wage of each year ${ }^{20}$ For the 1966 and 1981 samples, following Katz and Murphy (1992), I imputed to workers with topcoded earnings, annual earnings equal to 1.45 times the topcode amount. The factor 1.45 corresponds to the ratio of the estimated conditional average earnings of those with topcoded earnings by the topcode amount. From 1989 on, wage and salary incomes are collected into two separate variables, primary and secondary labor earnings, each with a different topcode amount. After adjusting for the topcodes, the primary and secondary earnings are added to form the annual earnings. For the primary earnings, workers with topcoded earnings were assigned the topcode until 1995. I multiply the values by 1.45 to obtain the primary earnings adjusted for topcodes. After 1996, topcoded workers were assigned the mean of all topcoded workers. I impute these workers the topcode times 1.45. For the secondary earnings, topcoded workers were assigned the topcoded value. I therefore impute these workers the topcode value times 1.45 .

\footnotetext{
${ }^{19}$ Conform to the literature, for the $1964-1975$ samples for which only interval of weeks worked are available, I imputed the mid-range of each interval.

${ }^{20}$ The series of nominal and real minimum wage rates are reported by the US department of Labor. The real series is obtained by deflating the nominal series by the CPI-U price index.
} 

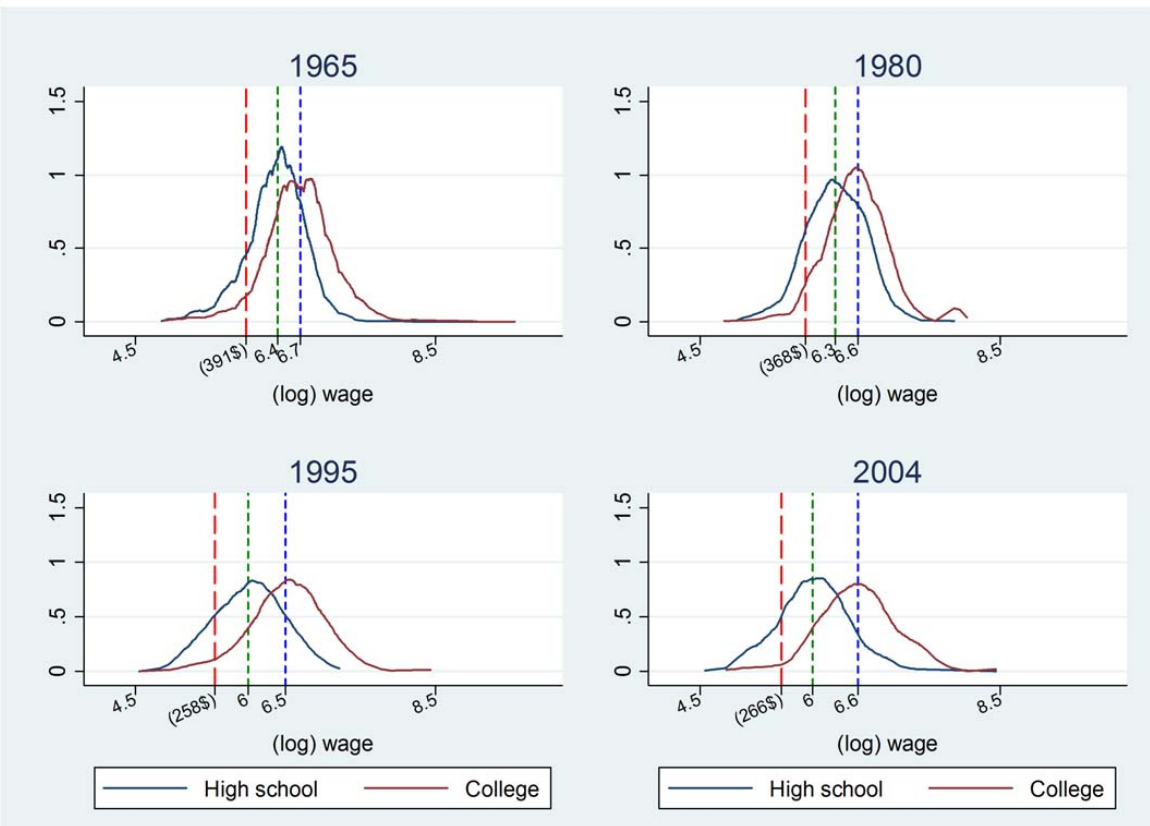

Figure 1: The US (log) wage distribution over time, in 1996 US dollars. Note: The red long dashed line represents the (log) wage at the firt decile of the overal distribution, the green and median of the (log) wage distribution of high-school and college graduates respectively. Data: CPS March supplements for 1966, 1981, 1996 and 2005. Sample: White males aged between 18 and 65 working full time full weeks. Wages are deflated using the CPI-U provided by the US department of Labor. 


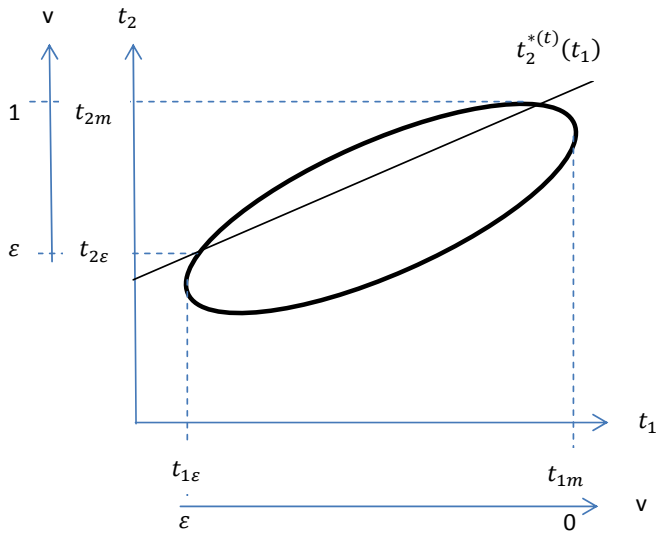

Figure 2: Skills self-selection and tasks assignment when skills are positively correlated in the population. 


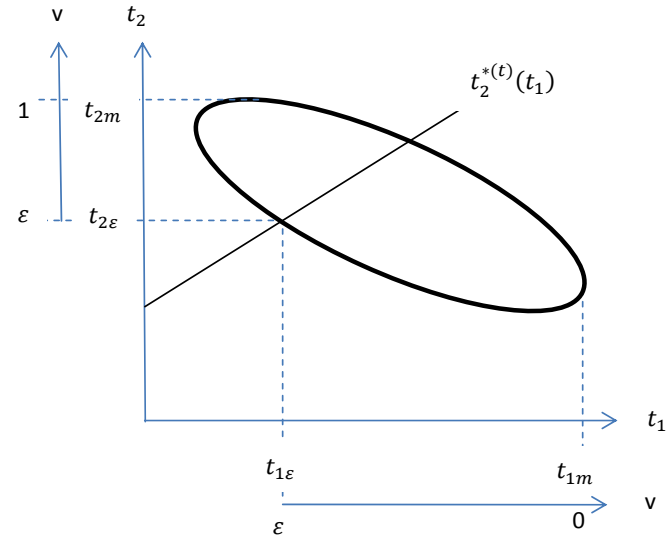

Figure 3: Skills self-selection and tasks assignment when skills are negatively correlated in the population. 


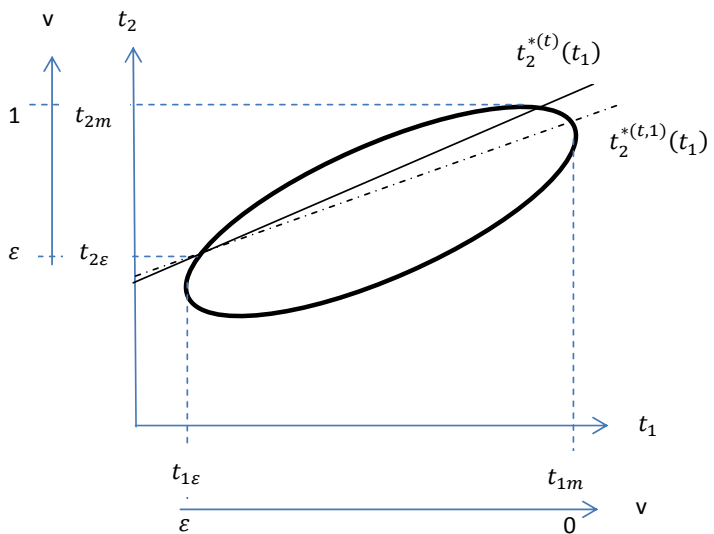

Figure 4: Skilled Biased Technical Change and the supply of skills when skills are positively correlated in the population and intellectual skills are more concentrated. 


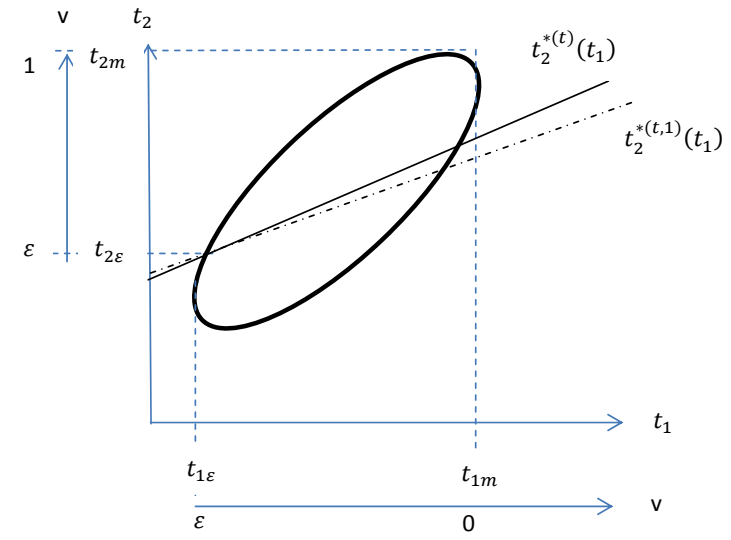

Figure 5: Skilled Biased Technical Change and the supply of skills when skills are positively correlated in the population and intellectual skills are less concentrated. 


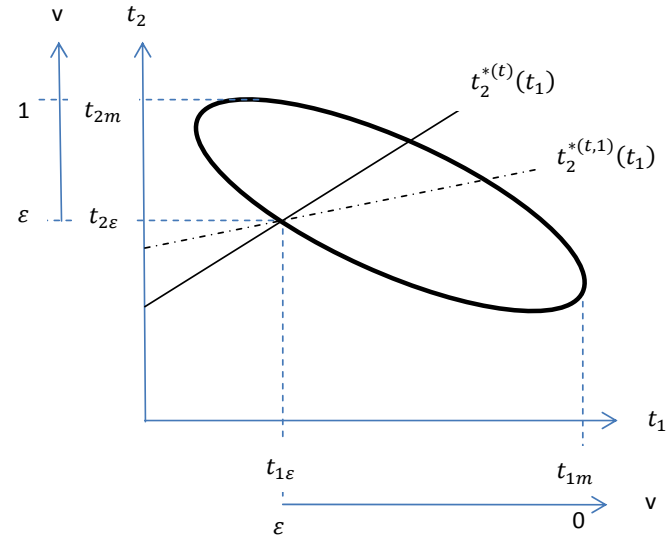

Figure 6: Skilled Biased Technical Change and the supply of skills when skills are negatively correlated in the population and intellectual skills are more concentrated. 


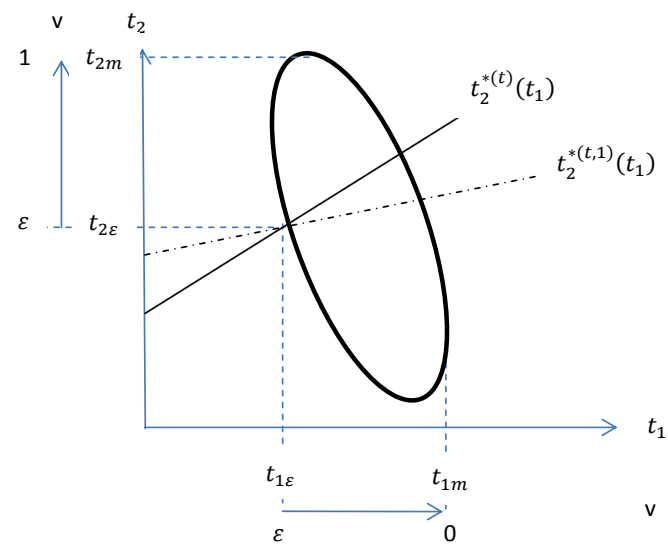

Figure 7: Skilled Biased Technical Change and the supply of skills when skills are negatively correlated in the population and intellectual skills are less concentrated. 